\title{
Cardiorenal syndrome
}

\author{
Sabry Omar MD, Ahmed Zedan MD
}

\begin{abstract}
Cardiovascular disease is the leading cause of death in patients with chronic kidney disease. Heart failure may lead to acute kidney injury and vice versa. Chronic kidney disease may affect the clinical outcomes in patients with cardiovascular disorders. Renal impairment with any degree of albuminuria has been increasingly recognized as an independent risk factor for cardiovascular events and heart failure hospitalizations, while chronic heart failure may cause chronic kidney disease. The bidirectional nature of these disorders contributes to the complexity and the composite definitions of cardiorenal syndromes. However, the most important clinical trials in heart failure tend to exclude patients with significant renal dysfunction. The mechanisms whereby renal insufficiency worsens the outcome in heart failure are not known, and several pathways could contribute to the "vicious heart/kidney circle." Traditionally, renal impairment has been attributed to the renal hypoperfusion due to reduced cardiac output and decreased systemic pressure. The hypovolemia leads to sympathetic activity, increased renin-angiotensin-aldosterone pathway, and arginine-vasopressin release. These mechanisms cause fluid and sodium retention, peripheral vasoconstriction, and volume overload. Therapy to improve renal dysfunction, reduce neurohormonal activation and ameliorate renal blood flow could lead to a reduction in mortality and hospitalization in patients with cardiorenal syndrome.
\end{abstract}

Key words: Cardiorenal syndrome, heart failure, acute kidney injury, chronic kidney disease, biomarkers, morbidity

The case below illustrates a common clinical problem in patients with both acute and chronic cardiac diseases, namely the development of renal dysfunction. This clinical presentation has been called a cardiorenal syndrome; this construct should lead to a better understanding of the interactions between cardiac and renal disorders and the effect of this interaction on management and outcomes. We have reviewed this topic by discussing the definitions, prevalence, pathophysiology, and treatment of cardiorenal syndromes.

Corresponding author: Sabry Omar, MD. Contact Information: E-mail: sabry.omar@ttuhsc.edu. DOI: 10.12746/swrccc2013.0101.004

\section{CASE}

A 68-year-old man with ischemic heart disease, type 2 diabetes mellitus, hypertension, and hyperlipidemia had been admitted with a ST segment elevation myocardial infarction three months previously. At this follow up visit he presented with gradually increasing shortness of breath, generalized swelling, and some abdominal distension. The patient was admitted to the coronary care unit. On admission, his blood pressure was 110/62 $\mathrm{mmHg}$, and he had bibasilar rales and bipedal pitting edema. The patient had oliguria with a urine output of $10 \mathrm{ml} /$ hour during the first day. The patient's baseline creatinine was $1.2 \mathrm{mg} / \mathrm{dl}$; on admission his creatinine was $2.6 \mathrm{mg} / \mathrm{dl}$ and his blood 
urea nitrogen was $54 \mathrm{mg} / \mathrm{dl}$. A renal ultrasound was unremarkable. An echocardiogram showed an ejection fraction of $32 \%$ with a dilated left ventricle. What has happened to this patient?

\section{Discussion}

\section{DEFINITIONS AND TYPES OF CARDIORENAL SYNDROMES}

Cardiorenal syndrome (CRS) is a complex patho physiological disorder of the heart and kidneys in which acute or chronic dysfunction in one organ causes acute or chronic dysfunction in the other organ. ${ }^{1-2}$ CRS is classified into five subtypes that recognize the potential underlying pathophysiological mechanisms (Table 1). ${ }^{2}$ Patients can move from one subtype to another depending on the clinical course. Since the current literature provides more information on CRS type 1 , our discussion emphasizes this syndrome.

\section{PreValence of CARDIORENAL SYNDROME}

Many patients (20-67\%) with heart failure have moderate to severe reductions in glomerular filtration rate (GFR) (less than $60 \mathrm{~mL} / \mathrm{min} / 1.73 \mathrm{~m} 2$ ); this renal dysfunction is associated with age, female gender, baseline chronic kidney disease, Caucasian American ethnicity, systolic and diastolic heart failure, diabetes, and hypertension. ${ }^{3-7}$ In a systematic review of 16 studies of more than 80,000 hospitalized and nonhospitalized patients with heart failure, moderate to severe kidney impairment (defined as an estimated GFR less than $53 \mathrm{ml} /$ minute, a serum creatinine of $1.5 \mathrm{mg} / \mathrm{dl}$ or higher, or a serum cystatin $\mathrm{C}$ of $1.56 \mathrm{mg} /$ dl or higher) was present in 29 percent. $^{8}$ The Acute Decompensated Heart Failure National Registry (ADHERE) database reported data on over 100,000 patients with heart failure requiring hospitalization. Approximately $30 \%$ had a diagnosis of chronic kidney disease (defined as a serum creatinine greater than $2.0 \mathrm{mg} / \mathrm{dL}$ ). The mean estimated GFR was $55 \mathrm{~mL} /$ $\mathrm{min} / \mathrm{m}^{2}$, and only $9 \%$ had a normal estimated GFR (defined as greater than $90 \mathrm{~mL} / \mathrm{min} / 1.73 \mathrm{~m}^{2}$ ). ${ }^{9}$ These studies demonstrate that renal insufficiency occurs very frequently in patients with cardiac diseases, especially in patients with heart failure.

Table 1 Cardiorenal syndrome classification

\begin{tabular}{|c|c|}
\hline Type & Definition \\
\hline $\begin{array}{l}\text { CRS type } 1 \text { (acute car- } \\
\text { diorenal syndrome) }\end{array}$ & $\begin{array}{l}\text { Abrupt worsening of cardiac function (e.g. acute cardiogenic shock, acute decompensation of chronic } \\
\text { heart failure or acute coronary syndrome) leading to acute kidney injury. }\end{array}$ \\
\hline $\begin{array}{l}\text { CRS type II (chronic } \\
\text { cardiorenal syndrome) }\end{array}$ & $\begin{array}{l}\text { Chronic abnormalities in cardiac function (e.g. chronic heart failure) causing progressive chronic kidney } \\
\text { disease. }\end{array}$ \\
\hline $\begin{array}{l}\text { CRS type III (acute re- } \\
\text { nocardiac syndrome) }\end{array}$ & $\begin{array}{l}\text { Abrupt worsening of renal function (e.g. acute kidney failure due to volume depletion or glomerulonephri- } \\
\text { tis) causing acute cardiac disorder (e.g. heart failure, arrhythmia, pulmonary edema). }\end{array}$ \\
\hline $\begin{array}{l}\text { CRS type IV (chronic } \\
\text { renocardiac syndrome) }\end{array}$ & $\begin{array}{l}\text { Chronic kidney disease (e.g. chronic glomerular disease) contributing to decreased cardiac function, } \\
\text { cardiac hypertrophy and / or increased risk of adverse cardiovascular events. }\end{array}$ \\
\hline $\begin{array}{l}\text { CRS type V (secondary } \\
\text { cardiorenal syndrome) }\end{array}$ & Systemic condition (e.g. diabetes mellitus, sepsis) causing both cardiac and renal dysfunction. \\
\hline
\end{tabular}




\section{Pathophysiology}

The term cardiorenal syndrome is an umbrella term for a worse outcome when these two organs fail simultaneously. However, the pathophysiology of kidney disease in heart failure is quite different from the pathophysiology of cardiovascular complications in chronic kidney disease. ${ }^{10}$ When renal parenchymal disease leads to cardiovascular complications, it is reasonable to call this presentation the renocardiac syndrome. ${ }^{11}$ CRS types 1 and 2 are frequently encountered in patients with heart disease, especially heart failure. Both acute heart failure leading to acute kidney injury and chronic heart failure leading to progressive renal insufficiency and chronic kidney disease represent conditions that may seem interchangeable. In some cases it difficult to distinguish between the two entities without the necessary time based information in the clinical history of the patient. The pathophysiology of CRS type 1, renal dysfunction in patients with decompensated heart failure, is complex. Reduced cardiac output and low mean arterial pressures cause renal hypoperfusion and passive congestion of the kidney, and this activates the renin-angiotensin system, reduces nitric oxide in the endothelium, activates the sympathetic nervous system, and induces inflammatory mediators. Deterioration of renal function can also occur in patients with acute decompensated heart with preserved left ventricular ejection fraction. ${ }^{12}$ Vascular factors, such as nitric oxide, prostaglandin, natriuretic peptides, and endothelin, may modulate renal perfusion independently of cardiac hemodynamics. ${ }^{13}$ The heart, kidneys, renin-angiotensin system, sympathetic nervous system, immune system, and endothelium interact through intricate feedback loops (Figure). Any imbalance in this complex system may cause deterioration in both cardiac and renal function. ${ }^{14}$ Cardiac biomarkers in CRS type 1 include troponin, CK-MB, BNP, NT-proBNP, myeloperoxidase, and ischemia modified albumin; renal biomarkers include serum cystatin $\mathrm{C}$, creatinine, and neutrophil gelatinase-associated lipocalin, and urinary kidney injury molecule-1, $\mathrm{IL}-18$, neutrophil gelatinase-associated lipocalin, and $\mathrm{N}$-acetyl-D-glucosaminadase. These markers reflect activation of hormonal, immunologic, inflammatory, and oxidative processes and are associated with an increased risk deterioration in renal function. ${ }^{15,16}$ These biomarkers have the potential to identify cardiorenal syndromes and predict outcomes and need more study. Patients with chronic heart failure can develop chronic renal failure (CRS type2) through a similar pathophysiology. Of course, adverse medication effects can contribute to the progression of renal disease.

The development of acute kidney injury as a primary event leading to cardiac dysfunction (CRS type 3 ) occurs frequently in critically ill patients but has not been systematically studied as much as CRS type 1. Acute kidney injury can affect the heart through several pathways. Fluid overload contributes to the development of pulmonary edema and atrial dilation leading to arrhythmias. Hyperkalemia can contribute to arrhythmias and may cause cardiac arrest. Untreated uremia affects myocardial contractility through the accumulation of myocardial depressant factors and can cause pericarditis. ${ }^{17}$ Partially corrected or uncorrected acidemia produces pulmonary vasoconstriction, which in some patients contributes to right-sided heart failure. Acidemia appears to have a negative inotropic effect and may, together with electrolyte imbalances, contribute to an increased risk of arrhythmias. ${ }^{18-20}$ Cardiac myocyte apoptosis and neutrophil infiltration are two of the most important contributors to the pathophysiology of myocardial infarction during acute kidney injury (renocardiac syndrome type 3), and transgenic models have shown that even apoptosis alone can lead to lethal heart failure. ${ }^{21}$

CRS type 4 recognizes the extreme burden of cardiovascular disease risk in patients with chronic kidney disease. The risk factors for cardiovascular disease (smoking, hypertension, dyslipidemia, age, and diabetes) also contribute to the progression of renal disease ${ }^{22}$ Nontraditional risk factors for cardiac disease, including biomarkers such as troponin, asymmetric dimethylarginine, plasminogen-activator inhibitor type 1, homocysteine, natriuretic peptides, C-reactive protein, serum amyloid A protein, and ischemia-modified albumin, progressively increase as GFR decreases. ${ }^{23,24}$ Many of these have an inde- 
pendent associations with subsequent vascular disease in chronic kidney disease. For example, B-type natriuretic peptide and the related $\mathrm{N}$-terminal pro-Btype natriuretic peptide are increased significantly in chronic kidney disease patients; these reflect the contribution of myocardial wall stress from hypertension and volume overload, ventricular hypertrophy, subclinical ischemia, cardiac remodeling, and fibrosis 25,26
Cardiorenal syndrome type 5 is defined as dysfunction of the heart and kidney secondary to systemic disease; it can occur simultaneously in acute conditions, such as sepsis, systemic lupus, toxin exposure (arsenic, snake bite, and scorpion bite), and Wagener's granulomatosis, or sequentially in chronic diseases, such as diabetes mellitus, hypertension, systemic amyloidosis, and chronic lead toxicity.
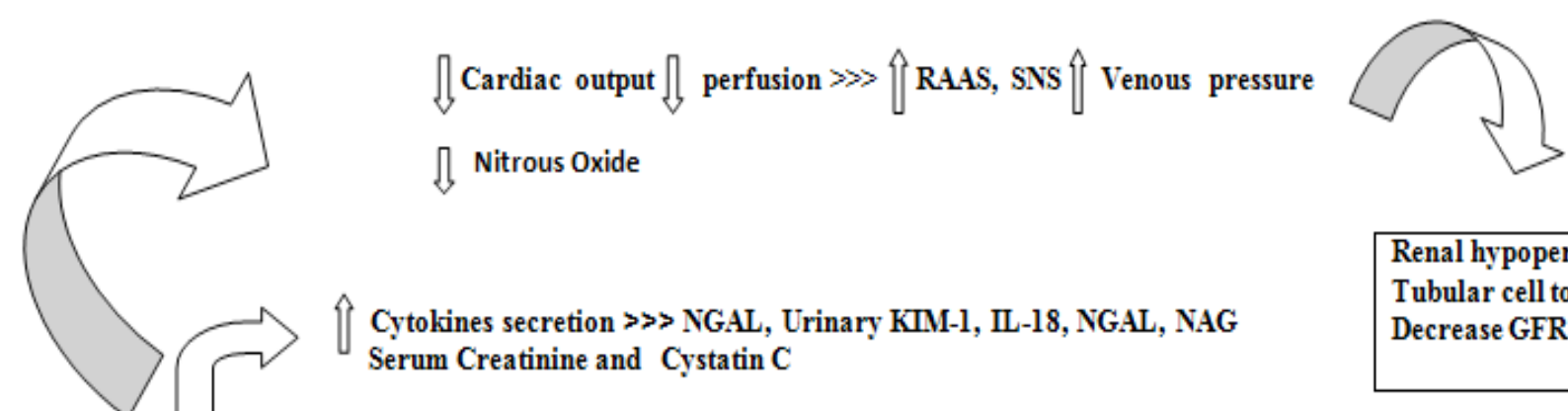

Renal hypoperfusion Tubular cell toxicity Decrease GFR

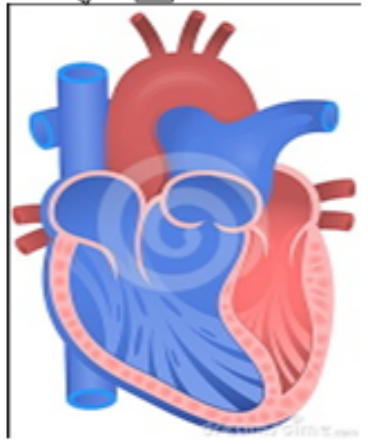

Acute heart failure Acute coronary syndrome Cardiogenic shock
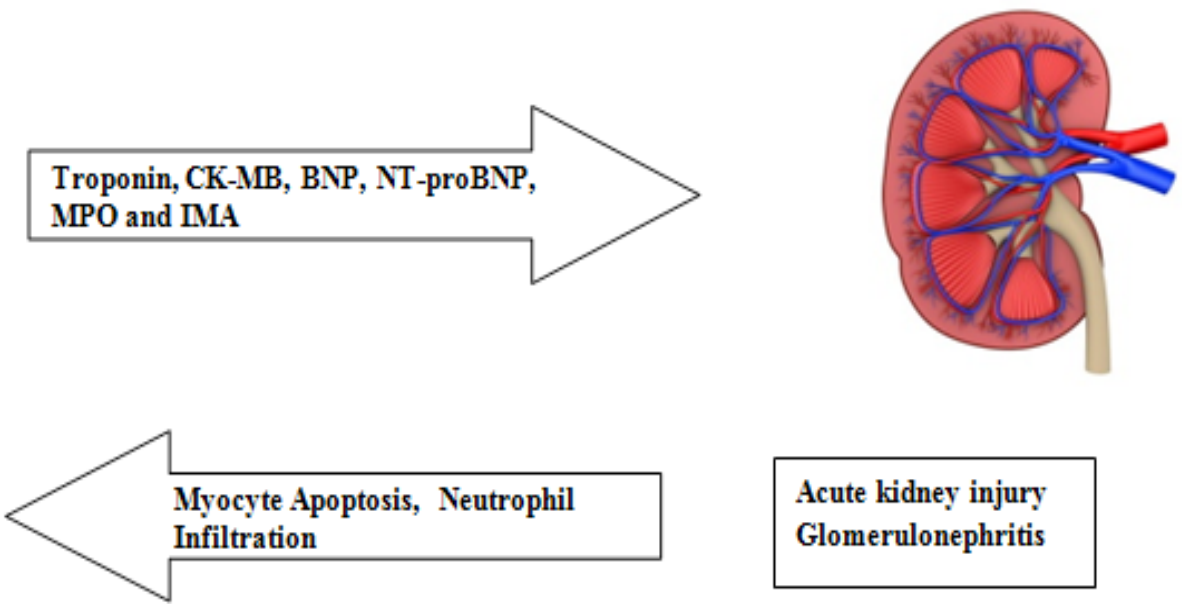

Acute kidney injury Glomerulonephritis

BNP, NT-proBNP

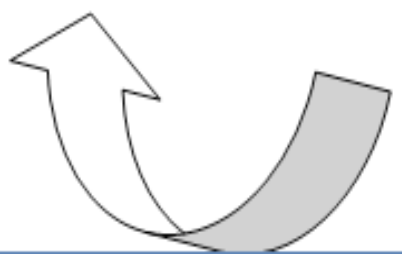

pulmonary edema $\leftarrow$ Fluid overload

Arrhythmias $\leftarrow$ Hyperkalemia

Contractility $\leftarrow$ MDS $\leftarrow$ Uremia

Pulmonary VC $\leftarrow$ Acidemia

Figure 1. Pathophysiology of cardiorenal syndrome.

Human neutrophil gelatinase- associated lipocalin (NGAL), Kidney injury molecule-1 (KIM-1), N-acetyl-D-glucosaminidase (NAG), Ischemia modified albumin (IMA), Renin-angiotensin-aldosteronesystem(RAAS), Sympathetic nervous system(SNS), Myocardial depressant substance (MDS), Brain natriuretic peptide (BNP), N-terminal pro hormone of brain natriuretic peptide (NT-proBNP), Interleukin-18(IL-18), creatine kinase -MB (CK-MB), Myeloperoxidase (MPO), Pulmonary vasoconstriction (Pulmonary VC), glomerular filtration rate(GFR). (Figure produced by Sabry A. Omar) 


\section{OUTCOME OF CARDIORENAL SYNDROME}

CRS type 1 is the most frequent disorder involving the heart and the kidney and is more frequent in patients with acute decompensated heart failure. Although CRS is less frequent in acute coronary syndrome patients, it is associated with longer hospital stays and with higher in-hospital mortality in these patients. Newsome et al reported a greater likelihood of progression to end-stage renal disease in patients with acute coronary syndrome complicated by acute kidney injury. ${ }^{27}$ In patients surviving ST elevation myocardial infarction, Goldberg found that persistent and increasing severity of acute kidney injury was associated with a higher risk of death. ${ }^{28}$ Gottlieb et al reported that $47 \%$ of patients admitted with acute decompensated heart failure developed CRS type 1 after three days of hospitalization; Cowie and coworkers found that $50 \%$ developed CRS type 1 after four days. ${ }^{29,30}$ Kociol retrospectively studied 20,063 Medicare beneficiaries hospitalized for acute decompensated heart failure and found that $17.8 \%$ developed acute kidney injury (defined as an increase in $\mathrm{Cr}$ of $0.3 \mathrm{md} / \mathrm{dl}$ ) and that $64.5 \%$ of those patient with acute kidney injury were readmitted and $35.4 \%$ died within one year. ${ }^{31}$ After adjustment for covariates, he found that acute kidney injury was associated independently with long-term mortality. Aronson et al reported that persistent worsening renal function after admission for acute decompensated heart failure was more likely in those with worse baseline kidney function. He investigated this outcome in a cohort of 467 patients admitted with acute decompensated heart failure. Worse renal function was defined as an absolute increase in serum creatinine of $0.5 \mathrm{mg} / \mathrm{dl}$. Transient deterioration was defined as a return to baseline within 30 days and persistent worsening renal function as a sustained increase in serum creatinine of $0.5 \mathrm{mg} /$ dl beyond 30 days. Transient and persistent deterioration in renal function occurred in $7.9 \%$ and $14.3 \%$, respectively. At six months, mortality was $17.3 \%$, $20.5 \%$, and $46.1 \%$ in those with neither, transient, and persistent worsening renal function, respectively $(P<$ 0.0001 for persistent vs. no change in renal function). This study strongly demonstrates a poor prognosis in patients with acute decompensated heart failure who have a persistent decrease in kidney function. ${ }^{32}$
In a study of acute kidney injury, the adjusted odds ratio for death from cardiac failure (7.7) was greater than the ratio from other causes, including hepatic failure (6.3), massive transfusion (5.3), age older than 60 years (3.7), respiratory failure (3.6), or neurologic failure (3.0). ${ }^{33}$ This study demonstrates that patients with acute kidney injury have complicated clinical courses and that cardiac mortality is frequent.

\section{TREATMENT}

Prevention of CRS is important since once the syndrome has started it is difficult to treat, is not completely reversible in some cases, and is associated with poor outcomes. Blood pressure control, use of drugs that block the renin-angiotensin-aldosterone system, aldosterone receptor blockers, beta adrenergic blockers, coronary artery disease risk factor modification and compliance with dietary and drug treatments, and a combination of nitrates and hydralazine when needed are the most basic preventive strategies suggested by the American Heart Association / American College of Cardiology for Stage A and B heart failure. ${ }^{34,35}$

Therapeutic approaches to patients with CRS are complex (Table 2). Vasodilators and loop diuretics are frequently used in cases of acute decompensated heart failure with CRS type $1 .^{36}$ However, loop diuretics predispose patients to electrolyte imbalance and hypovolemia leading to neurohumoral activation, reduced renal glomerular flow, and higher serum urea and creatinine levels. Felker reported that there were no significant differences in symptoms or rates of rehospitalization or death when diuretic therapy was administered by bolus compared to continuous infusion or at a high dose compared to a low dose in patients with acute decompensated heart failure. ${ }^{37}$ In this trial, serum creatinine increased by $0.3 \mathrm{mg} / \mathrm{dL}$ or more less frequently in those randomized to the bolus and lower-dose diuretic groups, suggesting less aggressive diuresis when feasible is a better strategy. In a randomized trial involving patients hospitalized for acute decompensated heart failure, worsening renal function, and persistent congestion, Bradley found 
that a stepped pharmacologic-therapy algorithm was superior to ultrafiltration for the preservation of renal function. Weight loss at 96 hours was similar with the two approaches, but ultrafiltration was associated with higher rates of adverse events. ${ }^{38}$ An earlier ultrafiltration vs. intravenous diuretics trial for patients hospitalized for acute decompensated heart failure with two or more signs of hypervolemia compared the safety and efficacy of veno-venous ultrafiltration and standard intravenous diuretic therapy for acute decompensated heart failure patients; this study had a different outcome. ${ }^{39}$ Two hundred patients were randomized to ultrafiltration or intravenous diuretics. At 48 hours, weight loss $(5.0 \pm 3.1 \mathrm{~kg}$ versus $3.1 \pm 3.5$ $\mathrm{kg} ; \mathrm{P}=.001)$ and net fluid loss $(4.6 \mathrm{~L}$ versus $3.3 \mathrm{~L}$; $\mathrm{P}=.001$ ) were greater in the ultrafiltration group. At 90 days, the ultrafiltration group had fewer patients rehospitalized for heart failure (16 of 89 [18\%] versus 28 of 87 [32\%]; $P=.037$ ), fewer heart failure rehospitalizations per patient $(0.22 \pm 0.54$ versus $0.46 \pm$ $0.76 ; \mathrm{P}=.022$ ), and fewer rehospitalization days per patient $(1.4 \pm 4.2$ versus $3.8 \pm 8.5 ; \mathrm{P}=.022)$. Changes in serum creatinine were similar in the two groups throughout the study. This trial showed that ultrafiltration produces greater weight and fluid loss than intravenous diuretics and reduces 90-day heart failure rehospitalizations and emergency department visits in patients with acute decompensated heart failure. These results support the hypothesis that removal of isotonic fluid by ultrafiltration rather than hypotonic urine by intravenous diuretics may explain the improved clinical benefits of ultrafiltration. ${ }^{40}$ However, ultrafiltration increases the complexity of care.

For CRS type 2 angiotensin converting enzyme inhibitors, beta-blockers, angiotensin receptor blockers, and aldosterone antagonists significantly reduce mortality and morbidity in congestive heart failure. ${ }^{41,42}$ In patients unable to tolerate these agents, hydralazine and nitrates can be used. Digoxin and diuretics improve symptoms in congestive heart failure but have no effect on mortality. ${ }^{43}$ However, vasodilators (e.g., nesiritide) can affect renal function and in some cases exacerbate renal injury. ${ }^{44}$ Vasopressin receptor 2 antagonists can improve hyponatremia in heart failure patients but have no clear survival benefit. ${ }^{45}$ Intra-aortic balloon pumps can be used for persistent hypotension in patients with acute decompensation. Depending upon pre-existing comorbidity and the underlying etiology, left ventricular assist devices can be used as a bridge to transplantation or cardiac surgery.

Management of CRS type 3 depends on optimal fluid status and perfusion pressures. To prevent kidney injury from low perfusion, volume depletion should be corrected. The core management of CRS type 3 is intravascular and extravascular volume control with either use of diuretics and various forms of renal replacement therapy or extracorporeal therapy and solute removal. In the setting of acute kidney, prevention of left ventricular volume overload is critical to maintain adequate cardiac output and systemic perfusion and also to protect against the vicious cycle that will worsen both cardiac and renal function. Because no evidence based guidelines have been proven effective in the management of CRS type 3 , the best approach is prevention. Optimization of fluid, avoidance of nephrotoxic agents, and correction of underlying disorders are the basic principles.

In CRS type 4 the presence of traditional cardiovascular risk factors represents an obvious target for therapy. Additional management strategies have mostly targeted those risk factors that are particular to or exaggerated in chronic kidney disease patients; these risk factors include anemia, hypertension, dyslipidemia, smoking, albuminuria, hyperhomocysteinemia, and malnutrition. The Study of Heart and Renal Protection (SHARP) trial included 3,023 end stage renal disease patients and 6,247 chronic kidney disease patients not on dialysis, and preliminary results showed a significant benefit with the combination of simvastatin and ezetimibe. ${ }^{46}$ In another study, 245 patients were randomized to three times weekly (conventional) or six times weekly (frequent) hemodialysis and followed up for 12 months. The frequent dialysis group had better outcomes, and the hazard ratio for death or increased left ventricular mass was 0.61 (95\% Cl, 0.46- 0.82). Important improvements in serum phosphate, control of hypertension, and avoidance of intradialytic hypotension were also noted in the frequent dialysis group. These results would strongly suggest that frequent dialysis may have an important role to play in the prevention and treatment 
Table 2 Cardiorenal syndrome treatment

\begin{tabular}{|c|l|}
\hline Type & \multicolumn{1}{c|}{ Treatment } \\
\hline CRS type 1 & $\begin{array}{l}\text { Vasodilators and loop diuretics are frequently used in cases of acute decompensated heart failure with CRS type } \\
1 .{ }^{34} \text { Ultrafiltration can be used if volume overload persists. }\end{array}$ \\
\hline CRS type 2 & $\begin{array}{l}\text { Angiotensin converting enzyme inhibitors, beta-blockers, angiotensin receptor blockers, and aldosterone antag- } \\
\text { onists significantly reduce mortality and morbidity in congestive heart failure. }{ }^{39,40} \text { In patients unable to tolerate } \\
\text { these agents, hydralazine and nitrates may be an option. Left ventricular assist devices can be used as a bridge } \\
\text { to transplantation or cardiac surgery. }\end{array}$ \\
\hline CRS type 3 & $\begin{array}{l}\text { The core management of CRS type 3 is intravascular and extravascular volume control with either use of diuretics } \\
\text { and various forms of renal replacement therapy or extracorporeal therapy and solute removal. Optimization of } \\
\text { fluid, avoidance of nephrotoxic agents, and correction of underlying disorders are the basic principles. Because } \\
\text { no evidence based guidelines have been proven effective in the management of CRS type 3, the best approach is } \\
\text { prevention. }\end{array}$ \\
\hline CRS type 4 & $\begin{array}{l}\text { Management strategies have mostly targeted cardiovascular risk factors that are particular to, or exaggerated in, } \\
\text { chronic kidney disease patients, such as anemia, hypertension, dyslipidemia, smoking, albuminuria, hyperho- } \\
\text { mocysteinemia, and malnutrition. Frequent dialysis in one study showed an important role in the prevention and } \\
\text { treatment of CRS type 4. }\end{array}$ \\
\hline CRS type 5 & $\begin{array}{l}\text { Treatment of the underlying disease(s) is the mainstay of treatment for CRS type 5. Associated cardiac and renal } \\
\text { complications warrant appropriate therapy as indicated on an individual basis. For example, removal of the source } \\
\text { of infection, antibiotic therapy, and other supportive measures in early goal directed therapy are indicated in pa- } \\
\text { tients with septic CRS type 5. }\end{array}$ \\
\hline
\end{tabular}

of CRS type $4 .^{47}$

Treatment of the underlying disease(s) is the mainstay of treatment for CRS type 5. Associated cardiac and renal complications warrant appropriate therapy as indicated on an individual basis. For example, removal of the source of infection, antibiotic therapy, and other supportive measures in early goal directed therapy are indicated in patients with septic CRS type 5.

\section{KEY PoINTS}

1. Acute and chronic cardiac dysfunction can have adverse effects on renal function.

2. Acute and chronic renal dysfunction can have adverse effects on cardiac function.

3. The development of dysfunction in a second organ (renal) as a consequence of the primary disor- der (cardiac) increases morbidity and mortality.

4. The cardiorenal syndrome classification may help clinicians organize their thinking about pathogenesis and patient management.

Author Affiliation: Sabry Omar, MD, is a resident in Internal Medicine at TTUHSC. Ahmed Zedan, MD, is a resident in Internal Medicine at TTUHSC in Lubbock, TX.

Received: 9/16/2012

Accepted: 12/19/2012

Reviewers: Kenneth Nugent, MD, Cihan Cevik, MD

Published electronically: 1/30/2013

Conflict of Interest Disclosures: None 


\section{REFERENCES}

1. Palazzuoli A, Ronco C. Cardio-renal syndrome: an entity that cardiologists and nephrologists should be dealing with collegially. Heart Fail Rev 2011; 16:503-50

2. Ronco C, Haapio M, Andrew A, et al. CardioRenal syndrome. J Am Coll Cardiol 2008; 52:1527-39.

3. Forman DE, Butler J, Wang Y, et al. Incidence, predictors at admission, and impact of worsening renal function among patients hospitalized with heart failure. J Am Coll Cardiol 2004; 43: 61-7.

4. Heywood JT, Fonarow GC, Costanzo MR, Mathur VS, Wigneswaran JR, Wynne J. ADHERE Scientific Advisory Committee and Investigators: High prevalence of renal dysfunction and its impact on outcome in 118,465 patients hospitalized with acute decompensated heart failure: A report from the ADHERE database. J Card Fail 2007; 13: 422- 430 5. Fonarow GC, Abraham WT, Albert NM, Gattis Stough W, Gheorghiade M, Greenberg BH, O'Connor CM, Pieper K, Sun JL, Yancy CW, Young JB. OPTIMIZE-HF Investigators and Hospitals: Influence of a performance-improvement initiative on quality of care for patients hospitalized with heart failure: Results of the organized program to initiate lifesaving treatment in hospitalized patients with heart failure (OPTIMIZE-HF). Arch Intern Med 2007; 167: 1493-1502

6. Masoudi FA, Baillie CA, Wang Y, Bradford WD, Steiner JF, Havranek EP, Foody JM, Krumholz HM. The complexity and cost of drug regimens of older patients hospitalized with heart failure in the United States, 1998-2001. Arch Intern Med 2005; 165: 2069-2076.

7. Ahmed A, Rich MW, Sanders PW, Perry GJ, Bakris GL, Zile MR, Love TE, Aban IB, Shlipak MG: Chronic kidney disease associated mortality in diastolic versus systolic heart failure: A propensity matched study. Am J Cardiol 2007; 99: 93-398.

8. Smith GL, Lichtman JH, Bracken MB, et al. Renal impairment and outcomes in heart failure: systematic review and meta-analysis. J Am Coll Cardiol 2006; 47:1987.

9. Adams KF, Fonarow GC, Emerman CL, et al. Characteristics and outcome of patients hospitalized for heart failure in the United States: rationale, design, and preliminary observations from the first 100,000 cases in the Acute Decompensated Heart Failure National Registry (ADHERE). Am Heart J 2005; 149: 209-16.

10. Schrier RW. Role of diminished renal function in cardiovascular mortality: marker or pathogenetic factor? J Am Coll Cardiol 2006; 47: 1-8.

11. Schrier RW. Cardiorenal versus renocardiac syndrome: Is there a difference? Nat Clin Pract Nephrol 2007; 3: 637.

12. Damman K, Voors AA, Hillege H, et al. Congestion in chronic systolic heart failure is related to renal dysfunction and increased mortality. Eur J Heart Fail 2010; 12:974-82.

13. Forman DE, Bulter J, Wang $Y$, et al. Incidence, predi cators at admission and impact of worsening renal function among patients hospitalized with heart failure. J Am Coll Cardiol 2004; 43:62-7.

14. Bongartz LG, Cramer MJ, Braam B. The cardiorenal connection. Hypertension 2004; 43:e14.

15. Damman K, van Veldhuisen DJ, Navis G,Voors AA, Hillege HL. Urinary neutrophil gelatinase associated lipocalin (NGAL), a marker of tubular damage, is increased in patients with chronic heart failure. Eur J Heart Fail 2008; 10:997-1000.

16. Damman K, Van Veldhuisen DJ, Navis G, Vaidya VS, Smilde TD, Westenbrink BD, et al. Tubular damage in chronic systolic heart failure is associated with reduced survival independent of glomerular filtration rate. Heart 2010; 96: 297-302.

17. Meyer TW, Hostetter TH. Uremia. N Engl J Med 2007; 357:1316-1325

18. Figueras J, Stein L, Diez V et al. Relationship between pulmonary hemodynamics and arterial $\mathrm{pH}$ and carbon dioxide tension in critically ill patients. Chest 1976; 70:466-472.

19. Brady JP, Hasbargen JA. A review of the effects of acidosis on nutrition in dialysis patients. Semin Dial 2000; 13:252-255.

20. McCullough PA, Sandberg KR. Chronic kidney disease and sudden death: strategies for prevention. Blood Purif 2004; 22: 136-142.

21. Bryant $\mathrm{D}$, Becker L, Richardson J, et al. Cardiac failure in transgenic mice with myocardial expression of tumor necrosis factor-alpha. Circulation 1998; 97:1375-81.

22. Ishani A, Grandits GA, Grimm RH, et al. Association of single measurements of dipstick proteinuria, estimated glomerular filtration rate, and hematocrit with 25 -year incidence of end-stage renal disease in the multiple risk factor intervention trial. J Am Soc Nephrol 2006; 17:1444-52.

23. Wang TJ, Gona P, Larson MG, et al. Multiple biomarkers for the prediction of first major cardiovascular events and death. N Engl J Med 2006; 355:2631-9.

24. Blankenberg S, McQueen MJ, Smieja M, et al. Comparative impact of multiple biomarkers and N-Terminal pro-brain natriuretic peptide in the context of conventional risk factors for the prediction of recurrent cardiovascular events in the Heart Outcomes prevention Evaluation (HOPE) Study. Circulation 2006; 114:2018

25. Austin WJ, Bhalla V, Hernandez-Arce I, et al. Correlation and prognostic utility of B-type natriuretic peptide and its aminoterminal fragment in patients with chronic kidney disease. Am J Clin Pathol 2006; 126: 506-12.

26. Maisel AS, Katz N, Hillege HL, et al. Biomarkers in kidney and heart disease. Nephrol Dial Transplant 2011; 26: 62-74. 
27. Newsome BB, Warnock DG, McClellan WM, et al. Long term risk of mortality and end-stage renal disease among the elderly after small increases in serum creatinine level during hospitalization for acute myocardial infarction. Arch Intern Med 2008; 168:609-16.

28. Goldberg A, Kogan E, Hammerman H, Markiewicz W, Aronson D. The impact of transient and persistent acute kidney injury on long-term outcomes after acute myocardial infarction. Kidney Int 2009; 76:900-6.

29. Cowie MR, Komajda M, Murray-Thomas T, Underwood J, Ticho B. Prevalence and impact of worsening renal function in patients hospitalized with decompensated heart failure: results of the prospective outcomes study in heart failure (POSH). Eur Heart J 2006; 27:1216-22.

30. Gottlieb SS, Abraham W, Butler J, et al. The prognostic importance of different definitions of worsening renal function in congestive heart failure. J Cardiac Fail 2002; 8:13641.

31. Kociol RD, Greiner MA, Hammill BG, et al. Long term outcomes of Medicare beneficiaries with worsening renal function during hospitalization for heart failure. Am J Cardiol 2010; 105:1786-93.

32. Aronson D, Burger AJ. The relationship between transient and persistent worsening renal function and mortality in patients with acute decompensated heart failure. J Card Fail 2010; 16(7):541-547.

33. Schwilk B, Wiedeck H, Stein B, et al. Epidemiology of acute renal failure and outcome of haemodiafiltration in intensive care. Intensive Care Med. 1997; 23:1204-11.

34. Hunt SA. ACC/AHA 2005 guideline update for the diagnosis and management of chronic heart failure in the adult: a report of the American College of Cardiology/ American Heart Association Task Force on Practice Guidelines (Writing Committee to Update the 2001Guidlines for the Evaluation and Management of Heart Failure). J Am Coll Cardiol 2005; 46:e1-e82.

35. Boerrigter GC-BL, Abraham WT, St. John Sutton MG, Heublein D, Kruger KM, Hill MR, McCullough PA,Burnett JC. Cardiac resynchronization therapy with biventricular pacing improves renal function in heart failure patients with reduced glomerular filtration rate. Circulation 2007; 116:II_405.

36. Hollenberg SM. Vasodilators in acute heart failure. Heart Fail Rev 2007; 12: 143-147.

37. Felker GM, Lee KL, Bull DA, Redfield MM, Stevenson LW, Goldsmith SR, et al. Diuretic strategies in patients with acute decompensated heart failure. NHLBI heart failure clinical research network. N Engl J Med 2011; 364: 797-805.

38. Bart BA, Goldsmith SR, Lee KL, at al. Ultrafiltration in Decompensated Heart Failure with Cardiorenal Syndrome. New Engl J Med 22012; 367: 2296-304.

39. Costanzo MR, Guglin ME, Saltzberg MT, et al. Ultrafiltration versus intravenous diuretics for patients hospitalized for acute decompensated heart failure. J Am Coll Cardiol 2007; 49: 675-83.

40. Ali SS, Olinger CC, Sobotka PA, et al. Loop diuretics can cause clinical natriuretic failure: a prescription for volume expansion. Congest Heart Fail 2009; 15:1-4.

41. The SOLVD Investigators. Effect of enalapril on survival in patients with reduced left ventricular ejection fractions and congestive heart failure. N Engl J Med 1991; 325:293-302.

42. Bangalore S, Messerli FH, Kostis JB, Pepine CJ. Cardiovascular protection using beta-blockers: a critical review of the evidence. J Am Coll Cardiol 2007; 50: 563-572.

43. Zannad F, Mebazaa A, Juilliere Y, Cohen-Solal A, Guize L, Alla F, Rouge P, Blin P, Barlet MH, Paolozzi L, Vincent C, Desnos M, Samii K. Clinical profile, contemporary management and one-year mortality in patients with severe acute heart failure syndromes: The EFICA study. Eur J Heart Fail 2006; 8:697-705.

44. Owan TE, Chen HH, Frantz RP, Karon BL, Miller WL, Rodeheffer RJ, Hodge DO, Burnett JC Jr, Redfield MM. The effects of nesiritide on renal function and diuretic responsiveness in acutely decompensated heart failure patients with renal dysfunction J Card Fail 2008; 14:267-275.

45. Ho JE, Teerlink JR. Role of tolvaptan in acute decompensated heart failure. Expert Rev Cardiovasc Ther 2008; 6: 601-608.

46. Baigent C, Landry MJ, Reith C, et al. The effects of lowering LDL with simivastatin plus ezetimibe in patients with chronic renal disease (Study of Heart and Renal Protection): a randomized placebo-controlled trial. Lancet 2011; 3772181-2192.

47. FHN Trial Group, Chertow GM, Levin NW, et al. In-center hemodialysis six times per week versus three times per week. N Engl J Med. 2010; 363:2287-300. 